\title{
Anxiety and Emotional Distress in Hyperemesis Gravidarum Patients (A Case-Control Study) in Zagazig University Hospitals, Egypt
}

\author{
Nora Nabil Hussien ${ }^{1,}$, , Aya Ahmed El Masry", Moustafa Mohammed Zaitoun², \\ Eman Roshdy Alsafi ${ }^{3}$ \\ ${ }^{1}$ Department of Family Medicine, Faculty of Medicine-Zagazig University, Zagazig, Egypt \\ ${ }^{2}$ Department of Gynecology and Obstetrics, Faculty of Medicine-Zagazig University, Zagazig, Egypt \\ ${ }^{3}$ Department of Psychiatry, Faculty of Medicine-Zagazig University, Zagazig, Egypt
}

\section{Email address:}

dr.nora_jana@yahoo.com (N.N. Hussien), ayaelmasry002@gmail.com(A. A. E1 Masry), mostafazaitoun54@hotmail.com(M. M. Zaitoun), e.roshdy_safy@hotmail.com(E.R. Alsafy)

*Corresponding author

\section{To cite this article:}

Nora Nabil Hussien, Aya Ahmed El Masry, Moustafa Mohammed Zaitoun, Eman Roshdy Alsafi. Anxiety and Emotional Distress in Hyperemesis Gravidarum Patients (A Case-Control Study) in Zagazig University Hospitals, Egypt. Journal of Family Medicine and Health Care. Vol. 5, No. 4, 2019, pp. 59-63. doi: 10.11648/j.jfmhc.20190504.14

Received: October 29, 2019; Accepted: November 19, 2019; Published: November 25, 2019

\begin{abstract}
Nausea and vomiting are common experiences in pregnancy and it is considered as a part of normal physiology. It affects about $75 \%$ of pregnant women without a known cause. In most cases, it is a mild and self-limited condition that can be controlled with conservative measures and has no adverse fetal outcomes. Women with severe nausea and vomiting during pregnancy (NVP) may have hyperemesis gravidarum (HG); an entity distinct from NVP, which if left untreated may lead to significant maternal and fetal morbidity. The objective of this study was to assess the presence and severity of anxiety in pregnant women with and without HG. The study is a case-control study on 52 pregnant women divided into two groups: cases hospitalized with the diagnosis of HG and healthy pregnant women as a control group. All mothers in the study were evaluated by Hamilton Anxiety Rating Scale (HAM-A) and General Health Questionnaire (GHQ-28). It was revealed that most of hyperemesis gravidarum cases suffered from severe anxiety while only (7.7\%) of healthy control had severe anxiety, with high statistical significant difference. The mean of Hamilton Anxiety Rating Scale (HAM-A) is statistically higher among hyperemesis gravidarum cases than healthy controls. Regarding General Health Questionnaire - 28 subscales; the mean score of somatic symptoms, social dysfunction and severe depression is statistically higher among hyperemesis gravidarum cases than healthy controls. It was concluded that anxiety and emotional distress were more common and severe in patients with HG.
\end{abstract}

Keywords: Hyperemesis Gravidarum, Anxiety, Emotional Distress

\section{Introduction}

Nausea and vomiting is very common in early pregnancy and it is considered as a part of normal physiology [1]. It affects about $75 \%$ of pregnant women without a known cause. In most cases, it is a mild and self-limited condition that can be controlled with conservative measures and has no adverse fetal outcomes, about $1 \%$ of women develop hyperemesis gravidarum (HG) which may result in adverse outcomes for the mother and fetus [2]. Hyperemesis gravidarum is excessive vomiting in pregnancy starting before the 22nd week of gestation and is the most common cause of hospitalization in the first trimester [3].

HG is defined as persistent vomiting and nausea, weight loss of more than $5 \%$ of pre-pregnancy body weight, ketonuria, electrolyte abnormalities (hypokalemia) and dehydration, resulting in poor quality of life and increased health care cost [4].

Despite the recognition of the adverse effects of HG on women's life and the severity of symptoms, the condition is underappreciated by health professionals, social workers and 
the general population $[5,6]$.

Previous studies showed an association between HG and depression and anxiety in pregnancy but the direction of this association was not clarified [7]. A relationship between the degree of nausea and vomiting and the risk of developing psychological distress including depression and anxiety has also been suggested, but researches showed conflicting results [8].

The initial research on psychological determinants of HG was evaluated by studies that claimed that HG was a form of somatization disorder. More recent studies on the psychological dimensions of HG have associated HG with symptoms of depression, anxiety and post-traumatic stress disorder [9]. However, these more recent studies suggest that psychological distress may be a reaction to the severity of HG symptoms rather than a part of its etiological pathways [10].

\section{Subjects and Method}

\subsection{Study Design}

A case-control study.

\subsection{Study Subjects}

Pregnant mothers were included if they were 18-35 years old with a single viable intrauterine pregnancy and in the first trimester of pregnancy. Pregnant mothers with a previous diagnosis of any psychiatric illness or under medication (as anti-depressants or anti-psychotics) or having a history of any medical problem (eg: endocrine abnormalities, gastrointestinal, cardiovascular or pulmonary disorders) were excluded from the study. Mothers who fulfil the study criteria were evaluated for presence of anxiety using Hamilton Anxiety Rating Scale (HAM-A) and emotional distress by the General Health Questionnaire-28 (GHQ-28).

\subsection{Sample Size}

According to a previous study done in 2015 [11]. Assuming that Beck Anxiety Inventory score in the case group is $(19.2 \pm 11)$ and in the control group is $(11.7 \pm 8.2)$ at a confidence level $95 \%$ and the power of the test is $80 \%$. The total sample size was calculated to be 52 (26 in each group) by open epi.

\subsection{Sampling Technique}

The sample is divided in to two groups: 1) The case group: cases hospitalized with the diagnosis of hyperemesis gravidarum by (persistent vomiting and nausea, weight loss of more than $5 \%$ of pre-pregnancy body weight, ketonuria, hypokalemia and dehydration) they were taken as a cluster in the critical pregnancy room in Gynecology and Obstetrics Hospital, and 2) The control group: normal pregnant females in the first trimester selected by systemic random sample technique from the antenatal care clinic.

\subsection{Data Collection Tools}

\subsubsection{Hamilton Anxiety Rating Scale (HAM-A)}

The Hamilton Anxiety Rating Scale (HAM-A, sometimes termed HARS) dating back to 1959 , is one of the first rating scales to measure the severity of perceived anxiety symptoms [12]. It consists of 14 symptom-defined elements, and caters for both psychological and somatic symptoms comprising: anxious mood, tension, fears, insomnia, intellectual, depressed mood, somatic symptoms, sensory, cardiovascular, respiratory, gastrointestinal, genitourinary, autonomic and observed behavior at interview. Each item is scored on a basic numeric scoring of 0 (not present) to 4 (severe) with a total score range of $0-56$ where $<17$ indicates mild severity, $18-24$ is considered mild-moderate severity $25-30$ moderate to severe.

\subsubsection{General Health Questionnaire-28}

The GHQ-28 was developed by Goldberg in 1978 and it is a screening tool to detect those likely to have or to be at risk of developing psychiatric disorders, the GHQ-28 is a 28 -item measure of emotional distress in medical settings. It is one of the most widely used and validated questionnaires to screen for emotional distress and possible psychiatric morbidity. The GHQ-28 has been divided into four subscales. These are: Somatic symptoms (items 1-7); anxiety/insomnia (items 8 14); social dysfunction (items 15-21), and severe depression (items 22-28) [13]. Each item is accompanied by four possible responses: Not at all, No more than usual, Rather more than usual, and Much more than usual. There are different methods to score the GHQ-28. It can be scored from 0 to 3 for each response with a total possible score ranging from 0 to 84 . A total score of 23/24 is the threshold for the presence of distress. Test-retest reliability has been reported to be high (0.78 to 00.9$)$ [14] and (Cronbach's $\alpha 0.9-0.95$ ) [15].

\subsection{Data Management}

Data were analyzed by computer using Statistical Package of Social Services version 24 (SPSS), Suitable statistical tests of significance were used after checked for normality. The results were considered statistically significant when the significant probability was less than $0.05(\mathrm{P}<0.05)$. P-value $<0.001$ was considered highly significant (HS), and P-value $\geq 0.05$ was considered statistically insignificant (NS).

\subsection{Administrative Design}

An official permission was obtained from (IRB) the Institutional Reviewing Board at the faculty of Medicine Zagazig University and a verbal consent was taken from mothers before collecting data. 


\section{Results}

Table 1. Determining severity of anxiety by Hamilton Anxiety Rating Scale (HAM-A) among the studied groups (No=52).

\begin{tabular}{|c|c|c|c|c|c|c|}
\hline \multirow{2}{*}{ Item } & \multicolumn{2}{|c|}{ Hyperemesis gravidarum $(\mathrm{N}=26)$} & \multicolumn{2}{|c|}{ Healthy control $(\mathrm{N}=26)$} & \multirow{2}{*}{$\mathbf{X}^{2}$} & \multirow{2}{*}{$P$ value } \\
\hline & No. & $\%$ & No. & $\%$ & & \\
\hline Mild & 0 & 0.0 & 6 & 23.1 & & \\
\hline Mild to moderate & 0 & 0.0 & 14 & 53.8 & 39.282 & $0.000 *(\mathrm{HS})$ \\
\hline Moderate to severe. & 2 & 7.7 & 4 & 15.4 & & \\
\hline Severe anxiety & 24 & 92.3 & 2 & 7.7 & & \\
\hline
\end{tabular}

$\mathrm{P}<0.05$ is significant.

This table shows that most of hyperemesis gravidarum cases suffered from severe anxiety, while only (7.7\%) of controls have severe anxiety with high statistical significant difference.

Table 2. Mean of Hamilton Anxiety Rating Scale (HAM-A) among the studied groups $(N o=52)$.

\begin{tabular}{|c|c|c|c|c|}
\hline Item & Hyperemesis gravidarum $(\mathrm{N}=26)$ & Healthy control $(\mathrm{N}=26)$ & Test & $P$ value \\
\hline Mean \pm SD & $40.53 \pm 4.73$ & $21.5 \pm 6.24$ & \multirow{2}{*}{ \# 7.000} & \multirow{2}{*}{$0.000 *(\mathrm{HS})$} \\
\hline Median (Range) & $42(28-45)$ & $22.5(7-35)$ & & \\
\hline
\end{tabular}

\# Mann Whitney $\mathrm{U}$ test. $\mathrm{P}<0.05$ is significant.

The mean of Hamilton Anxiety Rating Scale (HAM-A) is statistically higher among hyperemesis gravidarum cases than control.

Table 3. General Health Questionnaire - 28 (GHQ-28) among the studied groups.

\begin{tabular}{|c|c|c|c|c|c|c|}
\hline \multirow{2}{*}{ Item } & \multicolumn{2}{|c|}{ Hyperemesis gravidarum $(\mathrm{N}=\mathbf{2 6})$} & \multicolumn{2}{|c|}{ Healthy control $(\mathrm{N}=26)$} & \multirow{2}{*}{ Test } & \multirow{2}{*}{ P-value } \\
\hline & no & $\%$ & no & $\%$ & & \\
\hline \multicolumn{7}{|l|}{ General Health (GHQ-28) } \\
\hline 1. No emotional distress & 0 & 0.0 & 5 & 19.2 & \multirow{2}{*}{ FISHER } & \multirow{2}{*}{$0.051(\mathrm{NS})$} \\
\hline 2. Emotional distress & 26 & 100.0 & 21 & 80.8 & & \\
\hline \multicolumn{7}{|l|}{ Total (GHQ-28) score } \\
\hline 1. Mean \pm SD & $40.92 \pm 8.48$ & & 29. & & \#114.000 & $0.000 *(\mathrm{HS})$ \\
\hline
\end{tabular}

\#Mann Whitney $\mathrm{U}$ test. $\mathrm{P}<0.05$ is significant. NS: Not significant.

This table shows that the mean of GHQ-28 was higher in hyperemesis cases with high statistical significant difference.

Table 4. General Health Questionnaire - 28 (GHQ-28) subscales among the studied groups.

\begin{tabular}{|c|c|c|c|c|}
\hline Item & Hyperemesis gravidarum $(\mathrm{N}=26)$ & Healthy control $(\mathrm{N}=26)$ & Test \# & P-value \\
\hline \multicolumn{5}{|l|}{ Somatic symptoms } \\
\hline 1. Mean \pm SD & $14.77 \pm 2.74$ & $10.92 \pm 3.39$ & \multirow{2}{*}{113.000} & \multirow{2}{*}{$0.000 *(\mathrm{HS})$} \\
\hline 2. Median (Range) & $15(9-20)$ & $12(2-15)$ & & \\
\hline \multicolumn{5}{|l|}{ Anxiety/insomnia } \\
\hline 1. Mean $\pm \mathrm{SD}$ & $11.23 \pm 3.51$ & $9.92 \pm 3.87$ & \multirow{2}{*}{277.000} & \multirow{2}{*}{$0.261(\mathrm{NS})$} \\
\hline 2. Median (Range) & $10(7-18)$ & $9.5(2-17)$ & & \\
\hline \multicolumn{5}{|l|}{ Social dysfunction } \\
\hline 1. Mean $\pm \mathrm{SD}$ & $8.69 \pm 3.35$ & $6.81 \pm 2.45$ & \multirow{2}{*}{219.000} & \multirow{2}{*}{$0.027(\mathrm{~S})$} \\
\hline 2. Median (Range) & $7(5-16)$ & $6(1-13)$ & & \\
\hline \multicolumn{5}{|l|}{ Severe depression } \\
\hline 1. Mean $\pm \mathrm{SD}$ & $6.23 \pm 4.99$ & $2.27 \pm 3.11$ & \multirow{2}{*}{163.000} & \multirow{2}{*}{$0.001 *(\mathrm{HS})$} \\
\hline 2. Median (Range) & $7(0-15)$ & $0(0-8)$ & & \\
\hline
\end{tabular}

\#Mann Whitney $U$ test. $\mathrm{P}<0.05$ is significant. NS: Not significant.

The General Health Questionnaire - 28 subscales mean score of somatic symptoms, social dysfunction and severe depression is statistically higher among Hyperemesis gravidarum cases.

\section{Discussion}

This study according to Hamilton Anxiety Rating Scale (HAM-A) found that most of hyperemesis gravidarum cases 
suffered from severe anxiety $92.3 \%$ while only $7.7 \%$ of controls had severe anxiety as seen in table 1 with high statistical significant difference. The mean of Hamilton Anxiety Rating Scale (HAM-A) in table 2 is statistically higher among hyperemesis gravidarum cases than healthy controls (40.53 \pm 4.73 and $21.5 \pm 6.24)$ respectively $(\mathrm{P}<0.05$ is significant). This is consistent with the prospective nonrandomized cohort study over 79 patients with hyperemesis gravidarum and 71 healthy pregnant women in Istanbul, Turkey where mean among hyperemesis gravidarum cases is statistically higher than in non $(\mathrm{HG})$ cases $(3.16 \pm 1.80$ and $1.07 \pm 1.05)$ respectively ( $\mathrm{p}<0.01$ is significant) despite using a different scale the Brief Psychiatric Rating Scale (BPRS) for assessment of both groups [16].

These results also in agreement with another study used Beck Anxiety Inventory (BAI) for assessment of both groups and found that the mean among hyperemesis cases is statistically higher than (NVP) group $(17.8 \pm 12.8$ and $11.6 \pm$ 9.6) respectively $(p=0.011)$ [17].

And also consistent with a case-control study in which patients with $\mathrm{HG}$ had significantly higher Beck Anxiety Inventory (BAI) score than controls $(\mathrm{p}=0.049)$ also mean of HG cases is statistically higher than the control group (18.5 \pm 11.5 and $13.6 \pm 11.24)$ respectively [18]. And with a study by Kender who found that the mean scores of Beck Anxiety Inventory (BAI) of $\mathrm{HG}$ group were found to be statistically significant more than those of the control group $(19.22 \pm 10.96)$ and $(11.71 \pm 8.21)$ respectively $(\mathrm{p}<0.001)$ [19]. And also with Ezberci who found that the anxiety score in HG patients was significantly higher than that of the control group $(\mathrm{p}=0.045)$; the mean of Hospital Anxiety and Depression Scale (HADS-A subscale) score was (7.73 $\pm 3.86)$ in $\mathrm{HG}$ patients and $(6.70 \pm 3.31)$ in the control group [20].

On the other hand Beyazit and Sahin found that according to Beck Anxiety Inventory (BAI) severe anxiety is higher in hyperemesis gravidarum cases than in controls $(61.1 \%$ vs $10.8 \%)$ respectively with no statistical significance [21].

Another study in 2017 reported that woman with HG was 20.5 times more prone to having severe anxiety compared with healthy pregnant woman [22].

In this study table 3 demonstrated that General Health Questionnaire - 28 mean is statistically higher among hyperemesis gravidarum cases than controls $(40.92 \pm 8.48$ and $29.92 \pm 8.12$ ) respectively, somatic symptoms, social dysfunction and severe depression is statistically higher among Hyperemesis gravidarum cases $(\mathrm{P}<0.05)$ and this is close to the finding of Ezberci the mean Brief Disability Questionnaire (BDQ) score was $(11.2 \pm 4.40)$ in HG patients and $(8.5 \pm 3.31)$ in the control group. The physical and social disability score in $\mathrm{HG}$ patients were significantly higher than that of the control group $(p<0.0001)$ [20].

In this study all hyperemesis gravidarum cases suffered from emotional distress while only $80 \%$ of controls had distress this agree with the case-control study over 34 hospitalized pregnant women with hyperemesis gravidarum and 34 healthy pregnant women as controls in Ankara, Turkey who found that patients with HG had higher distress scores than those in the control group by using The Symptom Check List 90 Revised (SCL-90R) questionnaire results and the mean Global Severity Index (GSI) score of patients was $(1.03 \pm 0.57)$ and the control group's mean GSI score was $(0.64 \pm 0.48)$. The difference was statistically significant $(\mathrm{p}<0.004)$ [23].

The mean score of somatic symptoms is statistically higher among hyperemesis gravidarum cases than controls $(14.77 \pm 2.74)$ vs $(10.92 \pm 3.39)(\mathrm{P}<0.05)$ as seen in table 4, this agree with Pirimoglu by using The Symptom Check List 90 Revised (SCL-90-R) questionnaire who found that the difference between the two groups was also statistically significant, the mean somatization subscale scores were $(1.5114 \pm 0.71589)$ vs. $(0.9075 \pm 0.57545)$ respectively $(\mathrm{p}<$ $0.0001)$ [23].

\section{Conclusion}

This study concluded that anxiety and distress were more common and severe in patients with $\mathrm{HG}$. The findings indicated that psychological distress associated with HG was a direct consequence. The psychological aspect of hyperemesis gravidarum is very important and the psychological burden of hyperemesis shouldn't be neglected. So based on this study we recommend the following: 1) Health education for family physicians in primary care settings to increase awareness about the psychological aspects of hyperemesis gravidarum, 2) Direct the attention of family physicians to early recognize cases in primary care settings with proper management and referral to avoid adverse effects for the mother and fetus.

\section{References}

[1] London V, Grube S, Sherer D and Abulafia O. Hyperemesis Gravidarum: A Review of recent literature. Pharmacology. 2017; 100 (3-4): 161-171. doi: 10.1159/000477853.

[2] AAFP. Nausea and Vomiting of Pregnancy. Am Fam $\begin{array}{llll}\text { Physician. } \quad 2014 ; & 15 . & 89 & \text { (12): } 965-970 .\end{array}$ https://www.aafp.org/afp/2014/0615/p965.html.

[3] Nurmi M, Rautava P, Gissler M, Vahlberg T and Polo-Kantola P. Recurrence patterns of hyperemesis gravidarum. Am J. Obstet Gynecol. 2018; 219: 5 (469. e1-469. e10).

[4] Yeh C, Tsui K and Wang P. Hyperemesis gravidarum. J Chin Med Assoc. 2018; 81 (9): 755-756. doi: 10.1016/j.jcma.2017.09.001.

[5] Sykes C, Swallow B, Gadsby R, Barnie-Adshead A, Dean C, Moran E, et al. Seeking medical help for Nausea and Vomiting in Pregnancy (NVP) and Hyperemesis Gravidarum (HG) in primary care. MIDIRS. 2013; 9: 13-15.

[6] Dean C and Marsden J. Women's experiences of treatment for hyperemesis gravidarum in day case settings compared to hospital admissions. MIDIRS Midwifery Digest. 2017; 27 (2); 177-86. 
[7] Mitchell-Jones N, Gallos I, Farren J, Tobias A, Bottomley C and Bourne T. Psychological morbidity associated with hyperemesis gravidarum; a systematic review and metaanalysis. BJOG. 2017; 124 (1): 20-30. doi: 10.1111/14710528.14180 .

[8] Kjeldgaard H, Eberhard-Gran M, Benth J and Vikanes A. Hyperemesis gravidarum and the risk of emotional distress during and after pregnancy. Arch Womens Ment Health. 2017; 20 (6): 747-756. doi: 10.1007/s00737-017-0770-5.

[9] Balık G, Tekin Y and Kağıtcı M. Is there relationship between social support, psychological distress, mood disorders and hyperemesis gravidarum?. Journal of Obstetrics Gynaecology. 2015; 35 (7): 737-40.

[10] Groleau D, Benady-Chorney J, Panaitoiu A and Jimenez V. Hyperemesis Gravidarum in the context of migration: when the absence of cultural meaning gives rise to "blaming the victim". BMC Pregnancy and Childbirth. 2019; 19, 197. doi: 10.1186/s12884-019-2344-1

[11] Kender E, Yukse G, Ger C and Ozer U. Eating attitudes, depression and anxiety levels of patients with hyperemesis gravidarum hospitalized in an obstetrics and gynecology clinic. The Journal of Psychiatry and Neurological Sciences. 2015; 28 (119-126). doi: 10.5350/DAJPN2015280204.

[12] Hamilton M. The assessment of anxiety states by rating. Br J Med Psychol 1959; (32): 50-55. https://dcf.psychiatry.ufl.edu/files/2011/05/HamiltonAnxiety.pdf.

[13] Goldberg D. Manual of the General Health Questionnaire. NFER-Nelson, Windsor (1978).

[14] Robinson R and Price T. Post-Stroke depressive disorders: A follow-up study of 103 patients of stroke. Stroke. 1982; 13 (5): 635-41.

[15] Failde I, Ramos I and Fernandez-Palacín F. Comparison between the GHQ-28 and SF-36 (MH 1-5) for the assessment of the mental health in patients with ischaemic heart disease. Eur J Epidemiol. 2000; 16 (4): 311-6.
[16] Senturk M, Turan K, Cakmak Y and Budak M. Hyperemesis gravidarum, socio-cultural factors and maternal short psychiatric status. Medical Science and Discovery. 2015; 2 (6): 323-7. doi: 10.17546/msd.59756.

[17] Annagür B, Kerimoğlu Ö, Gündüz Ş and Tazegül A. Are there any differences in psychiatric symptoms and eating attitudes between pregnant women with hyperemesis gravidarum and healthy pregnant women?: J. Obstet. Gynaecol.2014;40 (4): 1009-1014 doi: 10.1111/jog.12274.

[18] Şimșek Y, Çelik Ö, Yılmaz E, Karaer A, Yıldırım E and Yoloğlu S. Assessment of anxiety and depression levels of pregnant women with hyperemesis gravidarum in a casecontrol study. Journal of the Turkish German Gynecological Association. 2012; 13 (1): 32-36. doi: 10.5152/jtgga.2012.01.

[19] Kender E, Yuksel G, Ger C and Ozer U. Eating attitudes, depression and anxiety levels of patients with hyperemesis gravidarum hospitalized in an obstetrics and gynecology clinic. The Journal of Psychiatry and Neurological Sciences.2015; $28 \quad$ (2): $\quad$ (119-126). doi: 10.5350/DAJPN2015280204.

[20] Ezberci I, Güven E, Ustüner I, Sahin F and Hocaoğlu C. Disability and psychiatric symptoms in hyperemesis gravidarum patients. Arch Gynecol Obstet. 2014; 289 (1): 5560. doi: 10.1007/s00404-013-2934-5.

[21] Beyazit F and Sahin B. Effect of nausea and vomiting on anxiety and depression levels in early pregnancy. Eurasian $\mathrm{J}$ $\begin{array}{llll}\text { Med. } 2018 ; & 50 & \text { (2): } & \text { (111-115). doi: }\end{array}$ 10.5152/eurasianjmed.2018.170320.

[22] Topalahmetoğlu Y, Altay M, Cırık D, Tohma Y, Çolak E and Çoşkun B. et al. Depression and anxiety disorder in hyperemesis gravidarum: A prospective case-control study. Turkish Journal of Obstetrics and Gynecology. 2017; 14 (4): (214-219). http://doi.org/10.4274/tjod.78477.

[23] Pirimoglu Z, Guzelmeric K, Alpay B, Balcik O, Unal O and Turan M. Psychological factors of hyperemesis gravidarum by using the SCL-90-R questionnaire. Clin Exp Obstet Gynecol. 2010; (37): 56-59. 